\title{
Clinical effects and safety of intra-arterial infusion therapy of cisplatin suspension in lipiodol combined with 5-fluorouracil versus sorafenib, for advanced hepatocellular carcinoma with macroscopic vascular invasion without extra-hepatic spread: A prospective cohort study
}

\author{
MASAHITO NAKANO $^{1}$, TAKASHI NIIZEKI $^{1 *}$, HIROAKI NAGAMATSU $^{2}$, MASATOSHI TANAKA $^{3}$, \\ RYOKO KUROMATSU $^{1}$, MANABU SATANI ${ }^{1}$, SHUSUKE OKAMURA ${ }^{1}$, HIDEKI IWAMOTO ${ }^{1}$, \\ SHIGEO SHIMOSE ${ }^{1}$, TOMOTAKE SHIRONO ${ }^{1}$, YU NODA ${ }^{1}$, HIRONORI KOGA ${ }^{1}$ and \\ TAKUJI TORIMURA ${ }^{1}$; THE KURUME LIVER CANCER STUDY GROUP OF JAPAN
}

\author{
${ }^{1}$ Division of Gastroenterology, Department of Medicine, Kurume University School of Medicine, Kurume, \\ Fukuoka 830-0011; ${ }^{2}$ Division of Gastroenterology, Department of Medicine, Yame General Hospital, Yame, Fukuoka 834-0034; \\ ${ }^{3}$ Division of Gastroenterology, Department of Medicine, Yokokura Hospital, Miyama, Fukuoka 839-0295, Japan
}

Received April 25, 2017; Accepted September 27, 2017

DOI: $10.3892 / \mathrm{mco} .2017 .1442$

\begin{abstract}
Although sorafenib and hepatic arterial infusion chemotherapy (HAIC) have been proven to improve prognosis in hepatocellular carcinoma (HCC) patients with macroscopic vascular invasion (MVI), the most appropriate approach remains unclear. The present multicenter, non-randomized, prospective cohort study aimed to compare the efficacy and safety of HAIC and sorafenib in patients with advanced HCC and MVI, without extra-hepatic spread (EHS) and Child-Pugh class A disease. The present study was performed between April 2008 and March 2014, and 64 HCC patients with MVI, without EHS and Child-Pugh class A disease were registered. Of these patients, 44 were treated with HAIC and 20 with sorafenib. HAIC involved cisplatin $(50 \mathrm{mg}$ fine powder in 5-10 ml lipiodol) and a continuous infusion of 5-fluorouracil (FU) (1,500 $\mathrm{mg} / 5$ days), which is referred to as new 5-FU and cisplatin therapy (NFP). The primary outcome was progression-free survival, and the secondary outcome was overall survival (OS). Clinical factors influencing OS and the therapeutic effect were identified using univariate and
\end{abstract}

Correspondence to: Dr Masahito Nakano, Division of Gastroenterology, Department of Medicine, Kurume University School of Medicine, 67 Asahi-machi, Kurume, Fukuoka 830-0011, Japan

E-mail: nakano_masahito@kurume-u.ac.jp

${ }^{*}$ Contributed equally

Key words: hepatic arterial infusion therapy, sorafenib, advanced hepatocellular carcinoma, macroscopic vascular invasion multivariate analyses. There were no differences in clinical factors between the two groups. The median progression-free survival was 5.1 and 9.5 months in the sorafenib and NFP groups, respectively $(\mathrm{P}=0.001)$. The complete response $(\mathrm{CR})$ or partial response (PR) rates were 10 and $71 \%$ in the sorafenib and NFP groups, respectively $(\mathrm{P}<0.001)$. The median OS in the sorafenib and NFP groups was 13.2 and 30.4 months, respectively $(\mathrm{P}=0.013)$. Multivariate analysis revealed that the independent predictors of survival were Child-Pugh score (5, $\mathrm{P}=0.022,95 \% \mathrm{CI}, 0.191-0.892)$, grade of portal vein invasion (brunch, $\mathrm{P}=0.009,95 \% \mathrm{CI}, 0.220-0.752$ ), and therapeutic effect (CR or PR, P<0.001, 95\% CI, 0.220-0.752), and the independent predictor of therapeutic effect was therapeutic regimen (NFP, $\mathrm{P}<0.001,95 \% \mathrm{CI}, 0.006-0.199)$. NFP should be the first choice for patients with advanced HCC and MVI, without EHS and Child-Pugh A disease.

\section{Introduction}

Hepatocellular carcinoma (HCC) is one of the most common malignancies globally (1-3). Among the various types of liver cancer, HCC is a major histological subtype and accounts for about four-fifths of all primary liver cancer cases (4). Recent advanced imaging procedures have led to increased detection of early stage HCC and improved survival, because curative therapies, such as hepatic resection, liver transplantation, and radiofrequency ablation, are possible in early stage patients (5). However, long-term survival remains unsatisfactory, because of high recurrence rates, even after curative therapy (6).

The development of advanced HCC with macroscopic vascular invasion (MVI) especially hinders the use of additional curative therapies, and therefore, this condition contributes to poor survival. MVI, including the presence of a tumor thrombus in the major portal vein, is known to be the 
most important negative risk factor for survival after resection or liver transplantation in patients with $\operatorname{HCC}(7,8)$. The median survival time of HCC patients with MVI has been reported to be 2-3 months $(9,10)$.

The landscape of systemic therapy for advanced HCC has changed with the advent of molecular-targeted therapy. Sorafenib, a relatively new molecular-targeted therapy for advanced HCC, was approved in Japan in May 2009 (11-13). Sorafenib is a multi-kinase inhibitor targeting the vascular endothelial growth factor receptor, platelet-derived growth factor receptor, and proto-oncoprotein c-Raf, among others $(14,15)$. The efficacy and safety of sorafenib in advanced HCC patients were demonstrated in the Sorafenib HCC Assessment Randomized Protocol (SHARP) (16), and Asia-Pacific studies (17). However, sorafenib monotherapy confers less than 3 months of actual survival benefit in both Western and Asian populations $(16,17)$.

Hepatic arterial infusion chemotherapy (HAIC) via an implanted port system has been reported to be a useful therapeutic option for advanced HCC, especially in patients with a major portal vein tumor thrombus (PVTT), and response to HAIC is considered an important prognostic factor (18-25). Various chemotherapeutic regimens are used for HAIC, and the combination of cisplatin and 5-fluorouracil (5-FU) is one of the most common regimens. Repeated HAIC using low-dose 5-FU and cisplatin (low-dose FP) has been shown to be useful in patients with advanced HCC and tumor thrombus in the portal vein $(18,19)$. Additionally, Nagamatsu et al investigated the efficacy and safety of the new combination therapy of cisplatin-lipiodol suspension and 5-FU for HCC with portal vein tumor thrombus, which was referred to as the new 5-FU and cisplatin therapy (NFP) (25). The authors demonstrated that the response rate was high at $86.3 \%$ and the median survival time (MST) was 33 months using NFP for unresectable HCC with portal vein tumor thrombus. While sorafenib and HAIC have been proven to improve prognosis in HCC patients with MVI (26), which is the better option remains to be determined.

The aim of the present multicenter, non-randomized, prospective cohort study was to investigate the efficacy and safety of NFP and compare the findings to those of sorafenib in patients with advanced HCC and MVI, without extra-hepatic spread (EHS) and Child-Pugh class A disease.

\section{Patients and methods}

Patients. The present study was performed between April 2008 and March 2014. A total of 64 HCC patients with MVI, without EHS and Child-Pugh class A disease were registered. Of the 64 patients, 20 were treated with sorafenib and 44 were treated with NFP. Prior to several treatments, all the patients in the sorafenib group were treated without NFP and all the patients in the NFP group were treated without sorafenib. The eligibility criteria for this study were as follows: i) Eastern Cooperative Oncology Group (ECOG) performance status of 0-2 (there were no patients with ECOG 2), ii) measurable disease using the Response Evaluation Criteria in Solid Tumors (RECIST) (27), iii) Child-Pugh class A liver function, iv) leukocyte count of $\geq 2,000 / \mathrm{mm}^{3}$, v) platelet count of $\geq 50 \times 10^{9} / 1$, vi) hemoglobin level of $\geq 8.5 \mathrm{~g} / \mathrm{dl}$, vii) serum creatinine level of $<1.5 \mathrm{mg} / \mathrm{dl}$, and viii) no ascites or encephalopathy. The enrolled patients were treated with sorafenib at one of the following 14 experienced member institutions of the Kurume Liver Cancer Study Group of Japan: Asakura Medical Association Hospital, Chikugo City Hospital, Kurume General Hospital, Kurume University Medical Center, Kurume University School of Medicine, Kyushu Medical Center, Nagata Hospital, Ōmuta City Hospital, Saga Social Insurance Hospital, Social Insurance Tagawa Hospital, St. Mary's Hospital, Tobata Kyoritsu Hospital, Yame General Hospital, and Yokokura Hospital. The primary outcome of this study was radiologic progression-free survival, which was defined as the time from the initiation of treatment to the date of disease progression. The secondary outcome of this study was overall survival (OS), which was defined as the time from the initiation of treatment to the date of death or the patient's last follow-up. Relevant data from all patient clinical records, including medical history, laboratory results, radiological findings, histological results, and survival data, were prospectively collected.

The study protocol was approved by the Ethics Committee of Kurume University (no. 09227) and the University Hospital Medical Information Network (UMIN) Center (no. UMIN000004022), and conformed to the guidelines of the 1975 Declaration of Helsinki. Patients were provided comprehensive information on the details of the clinical study, and each patient provided written informed consent prior to participation.

Diagnosis. HCC was either confirmed histologically or diagnosed using non-invasive criteria according to the European Association for the Study of Liver (28). Intrahepatic lesions and vascular invasion were diagnosed using a combination of contrast-enhanced computed tomography (CT), magnetic resonance imaging (MRI), ultrasonography (US), and digital subtraction angiography. Additionally, $\alpha$-fetoprotein (AFP), lens culinaris agglutinin-reactive fraction of AFP (AFP-L3), and des- $\gamma$-carboxy prothrombin (DCP) serum levels were measured up to 1 month before treatment. Hepatic functional reserve was evaluated before treatment using the Child-Pugh scoring system. Tumor stage was determined according to the Barcelona Clinic Liver Cancer (BCLC) staging classification (29).

Sorafenib treatment. Performance status was used to determine the initial sorafenib dose, at the discretion of the chief physician. Discontinuation and dose reduction were allowed based on tolerance. Side effects of sorafenib treatment were documented according to the National Cancer Institute's Common Terminology Criteria for Adverse Events (CTCAE), version 4.0. Treatments were discontinued upon development of CTCAE grade 3 or higher adverse events with the exception of a platelet count of $<25 \times 10^{9} / 1$ and a leukocyte count of $<1,500 / \mathrm{mm}^{3}$.

Implantation of arterial catheter. An indwelling catheter (5-Fr W-spiral Catheter; Piolax, Tokyo, Japan) was inserted through the femoral or brachial artery, with the distal end of the catheter extended into the hepatic artery or gastroduodenal artery, and the proximal end connected to the port system (SOPH-A-PORT; Sophisa, Besançon, France), which was 
Table I. Patient characteristics $(n=64)$.

\begin{tabular}{|c|c|c|c|}
\hline Variables & Sorafenib $(n=20)$ & $\operatorname{NFP}(n=44)$ & P-value \\
\hline Age (years) & $65.4 \pm 8.1$ & $63.4 \pm 10.0$ & 0.426 \\
\hline Sex, n (\%) & & & 0.519 \\
\hline Male & $17(85)$ & $33(75)$ & \\
\hline Female & $3(15)$ & $11(25)$ & \\
\hline HBs antigen, $\mathrm{n}(\%)$ & & & 0.238 \\
\hline Present & $5(25)$ & $6(14)$ & \\
\hline Absent & $15(75)$ & $38(86)$ & \\
\hline $\mathrm{HCV}$ antibody, n (\%) & & & 0.054 \\
\hline Present & $8(40)$ & $29(66)$ & \\
\hline Absent & $12(60)$ & $15(34)$ & \\
\hline Child-Pugh score, n (\%) & & & 0.787 \\
\hline 5 & $10(50)$ & $19(43)$ & \\
\hline 6 & $10(50)$ & $25(57)$ & \\
\hline $\mathrm{AFP}(\mathrm{ng} / \mathrm{ml}), \mathrm{n}(\%)$ & & & 0.787 \\
\hline$<1,000$ & $5(25)$ & $22(50)$ & \\
\hline$\geq 1,000$ & $15(75)$ & $22(50)$ & \\
\hline $\mathrm{DCP}(\mathrm{AU} / \mathrm{ml}), \mathrm{n}(\%)$ & & & 0.791 \\
\hline$<1,000$ & $12(60)$ & $24(55)$ & \\
\hline$\geq 1,000$ & $8(40)$ & $20(45)$ & \\
\hline Previous treatment, n (\%) & & & 0.787 \\
\hline Present & $12(60)$ & $28(64)$ & \\
\hline Absent & $8(40)$ & $16(36)$ & \\
\hline Maximum tumor size, $\mathrm{mm}$ & $74.3 \pm 54.2$ & $74.2 \pm 33.3$ & 0.995 \\
\hline Grade of portal vein invasion, $\mathrm{n}(\%)$ & & & 0.124 \\
\hline Trunk & $5(25)$ & $4(9)$ & \\
\hline Branch & $15(75)$ & $40(91)$ & \\
\hline Hepatic vein invasion, n (\%) & & & 0.486 \\
\hline Present & $2(10)$ & $8(18)$ & \\
\hline Absent & $18(90)$ & $36(82)$ & \\
\hline
\end{tabular}

NFP, new 5-fluorouracil and cisplatin therapy; HB, hepatitis B; HCV, hepatitis C virus; AFP, $\alpha$-fetoprotein; DCP, des- $\gamma$-carboxy prothrombin Results are presented as $\mathrm{n}(\%)$ or mean \pm standard deviation.

Table II. Therapeutic effects in all patients $(n=64)$.

\begin{tabular}{lcr}
\hline Therapeutic effect & Sorafenib $(\mathrm{n}=20)$ & NFP $(\mathrm{n}=44)$ \\
\hline CR & $0(0)$ & $10(23)$ \\
PR & $2(10)$ & $21(48)$ \\
SD & $8(40)$ & $8(18)$ \\
PD & $10(50)$ & $5(11)$ \\
\hline
\end{tabular}

NFP, new 5-fluorouracil and cisplatin therapy; CR, complete response; $\mathrm{PR}$, partial response; $\mathrm{SD}$, stable disease; $\mathrm{PD}$, progressive disease Results are presented as n (\%).

implanted subcutaneously. The right gastric, gastroduodenal, and posterior superior pancreaticoduodenal arteries were occluded with VortX coils (Boston Scientific, Marlborough, MA, USA) to prevent gastroduodenal ulcers caused by anticancer agents.

Therapeutic NFP regimen. The NFP regimen comprised a combination of $50 \mathrm{mg}$ cisplatin in 5-10 ml lipiodol and a continuous infusion of 5-FU (1,500 mg/5 days). On day 1 of treatment, cisplatin with lipiodol was injected through the reservoir catheter followed by 5 -FU $(250 \mathrm{mg})$. Then, $5-\mathrm{FU}$ (1,250 mg) was continuously infused using a balloon pump (SUREFUSER PUMP, Nipro Pharma Corporation, Osaka, Japan) for 5 days. This regimen was administered once a week during the first 2 weeks of admission, and then, the combination of 20-35 mg cisplatin with 2-5 ml lipiodol and 500-1,000 mg 5-FU was infused every 2 weeks at the out-patient department as long as possible. Treatment was discontinued in case of the occurrence of grade 3 or higher adverse effects according 
Table III. Univariate and multivariate analyses of overall survival.

\begin{tabular}{|c|c|c|c|}
\hline \multirow[b]{2}{*}{ Variable } & \multirow[b]{2}{*}{ Univariate analysis P-value } & \multicolumn{2}{|c|}{ Multivariate analysis } \\
\hline & & $95 \%$ CI & P-value \\
\hline Age ( $\geq 65$ years $)$ & 0.456 & & \\
\hline Sex (male) & 0.242 & & \\
\hline HBs Ag (+) & 0.631 & & \\
\hline $\mathrm{HCV} \mathrm{Ab} \mathrm{(+)}$ & 0.661 & & \\
\hline Child-Pugh score (5) & 0.004 & $0.191-0.892$ & 0.022 \\
\hline $\operatorname{AFP}(\geq 1,000 \mathrm{ng} / \mathrm{ml})$ & 0.169 & & \\
\hline $\mathrm{DCP}(\geq 1,000 \mathrm{mAU} / \mathrm{ml})$ & 0.452 & & \\
\hline Previous treatment (present) & 0.457 & & \\
\hline Maximum tumor size ( $\geq 100 \mathrm{~mm})$ & 0.267 & & \\
\hline Grade of portal vein invasion (Branch) & $<0.001$ & $0.118-0.614$ & 0.002 \\
\hline Hepatic vein invasion (present) & 0.176 & & \\
\hline Regimen (NFP) & 0.015 & & \\
\hline Therapeutic effect (CR or PR) & $<0.001$ & $0.220-0 \cdot 752$ & 0.009 \\
\hline
\end{tabular}

CI, confidence interval; HB, hepatitis B; HCV, hepatitis C virus; AFP, $\alpha$-fetoprotein; DCP, des- $\gamma$-carboxy prothrombin; NFP, new 5-fluorouracil and cisplatin therapy; $\mathrm{CR}$, complete response; $\mathrm{PR}$, partial response.

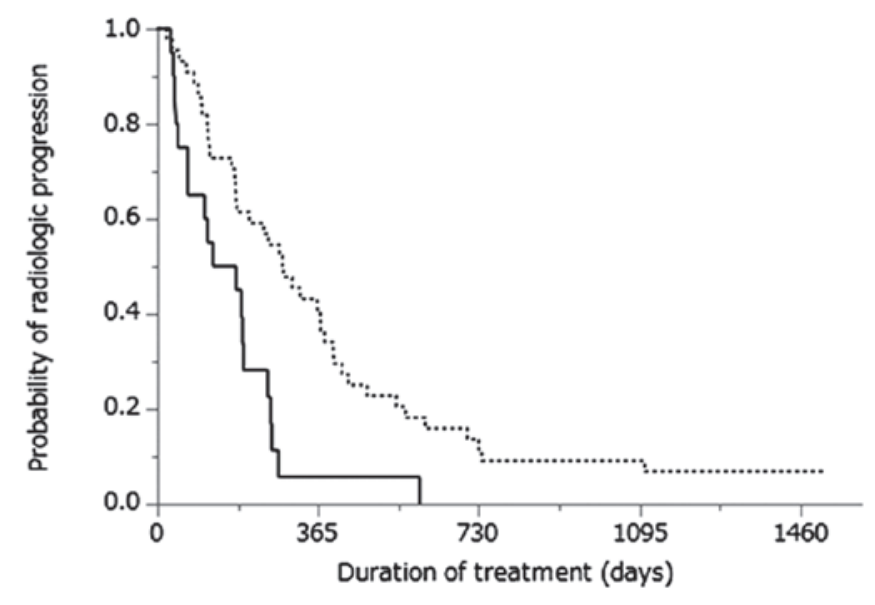

Figure 1. Kaplan-Meier analysis of progression-free survival in patients treated with sorafenib (solid line; $n=20$ ) and those treated with NFP (dotted line; $n=44)$. The median survival times were 5.1 and 9.5 months, respectively $(\mathrm{P}=0.001)$.

to the ECOG classification (30), with the exception of total bilirubin $>3.0 \mathrm{mg} / \mathrm{dl}$, platelet count $<25 \times 10^{9} / 1$, and leukocyte count $<1,500 / \mathrm{mm}^{3}$.

Assessment of tumor response. To determine the therapeutic effect, baseline tumor measurements were obtained within 1 month before treatment by combining the largest diameters of selected target lesions in each patient as measured using CT or MRI. CT or MRI was performed 4-6 weeks after the initial treatment cycle and every 2-3 months thereafter. The therapeutic effect was determined according to the best overall response, which was defined by the RECIST as follows: Complete response (CR), disappearance of all measurable lesions for $>4$ weeks; partial response (PR), $>30 \%$ decrease in the sum of the largest target-lesion diameters and no development of a new lesion for $>4$ weeks; progressive disease (PD), $>25 \%$ increase in the sum of the largest target-lesion diameters or appearance of a new lesion; and stable disease (SD), neither PR nor PD seen for $>8$ weeks (31). Patients who died before their first radiographic assessment were classified as having PD. Data from patients who died without tumor progression were censored. The response rate was defined, on the basis of independent radiologic review, as the percentage of patients whose best-response RECIST rating of CR or PR was maintained for at least 1 month after the first demonstration of such a rating. The disease-control rate was defined, on the basis of independent radiologic review, as the percentage of patients whose best-response RECIST rating of $\mathrm{CR}, \mathrm{PR}$, or SD was maintained for at least 1 month after the first demonstration of such a rating.

Statistical analysis. Baseline patient characteristics were analyzed using descriptive statistical methods. Survival curves were calculated using the Kaplan-Meier method. Univariate analysis of survival curves was performed using the log-rank test. $\mathrm{P}<0.05$ was considered statistically significant. The Cox proportional-hazards model was used to evaluate the interaction between baseline characteristics and overall survival or therapeutic effect. The JMP software (SAS Institute, Inc., Cary, NC, USA), version 12, was used for all analyses.

\section{Results}

Patient characteristics. The sorafenib therapy group $(\mathrm{n}=20)$ included $17(85 \%)$ men and $3(15 \%)$ women, with a mean age of 65.4 years (Table I). Chronic hepatitis $\mathrm{C}$ virus infection was the predominant cause of $\mathrm{HCC}(\mathrm{n}=8 ; 40 \%)$, followed by chronic hepatitis $\mathrm{B}$ virus infection $(\mathrm{n}=5 ; 25 \%)$. Of the 20 patients, $10(50 \%)$ had a Child-Pugh score of 5 and $10(50 \%)$ had a 
Table IV. Univariate and multivariate analyses of the comparison of patient characteristics based on therapeutic effect.

\begin{tabular}{|c|c|c|c|c|c|}
\hline \multirow[b]{2}{*}{ Variables } & \multirow{2}{*}{$\begin{array}{c}C R+P R \\
(n=31)\end{array}$} & \multirow{2}{*}{$\begin{array}{c}\mathrm{SD}+\mathrm{PD} \\
(\mathrm{n}=33)\end{array}$} & \multirow{2}{*}{$\begin{array}{c}\text { Univariate analysis } \\
\text { P-value }\end{array}$} & \multicolumn{2}{|c|}{ Multivariate analysis } \\
\hline & & & & $95 \% \mathrm{CI}$ & P-value \\
\hline Age ( $\geq 65$ years) & $68.3 \pm 9.5$ & $68.6 \pm 8.6$ & 0.892 & & \\
\hline Sex (male) & $25 / 6$ & $25 / 8$ & 0.763 & & \\
\hline Child-Pugh score (5) & $13 / 18$ & $22 / 11$ & 0.078 & & \\
\hline $\operatorname{AFP}(\geq 1,000 \mathrm{ng} / \mathrm{ml})$ & $19 / 12$ & $18 / 15$ & 0.248 & & \\
\hline DCP $(\geq 1,000$ mAU/ml $)$ & $9 / 22$ & $14 / 19$ & 0.042 & & \\
\hline Previous treatment (present) & $21 / 10$ & $23 / 10$ & 0.140 & & \\
\hline Maximum tumor size ( $\geq 100 \mathrm{~mm})$ & $19 / 12$ & $31 / 2$ & 0.045 & $1.961-75.12$ & 0.007 \\
\hline Grade of portal vein invasion (Branch) & $5 / 26$ & $4 / 29$ & 0.729 & & \\
\hline Hepatic vein invasion (present) & $6 / 25$ & $4 / 29$ & 0.326 & & \\
\hline Regimen (NFP) & $18 / 13$ & $2 / 31$ & $<0.001$ & $0.006-0.199$ & $<0.001$ \\
\hline
\end{tabular}

CR, complete response; PR, partial response; SD, stable disease; PD, progressive disease, $\mathrm{CI}$, confidence interval; AFP, $\alpha$-fetoprotein; DCP, des- $\gamma$-carboxy prothrombin; NFP, new 5 -fluorouracil and cisplatin therapy Results are presented as $n$ or mean \pm standard deviation.

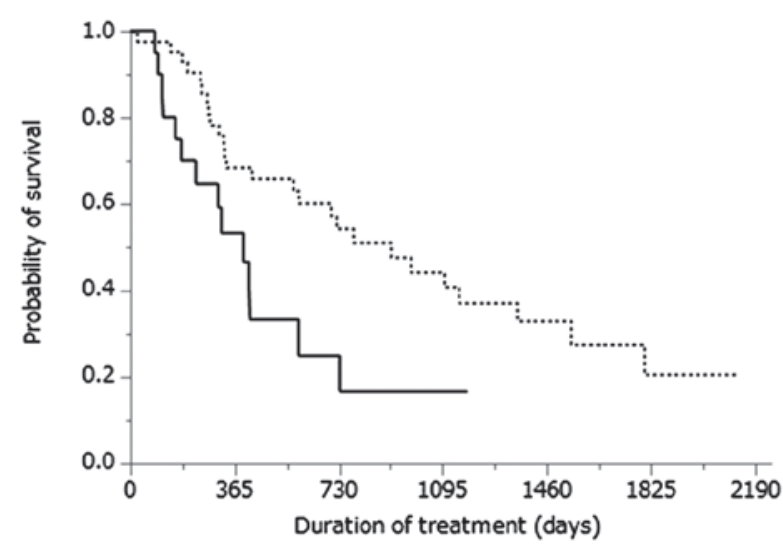

Figure 2. Kaplan-Meier analysis of overall survival in patients treated with sorafenib (solid line; $\mathrm{n}=20$ ) and those treated with NFP (dotted line; $\mathrm{n}=44$ ). The median survival times were 13.2 and 30.4 months, respectively $(\mathrm{P}=0.013)$.

Child-Pugh score of 6. Prior to sorafenib therapy, $12(60 \%)$ patients received previous treatment. HCC showed portal vein invasion, with $5(25 \%)$ patients having main trunk invasion and $15(75 \%)$ having first or second branch invasion, and the mean size was $74.3 \mathrm{~mm}$.

On the other hand, the NFP group $(n=44)$ included $33(75 \%)$ men and $11(25 \%)$ women, with a mean age of 63.4 years (Table I). Chronic hepatitis $\mathrm{C}$ virus infection was the predominant cause of HCC $(n=29 ; 66 \%)$, followed by chronic hepatitis $B$ virus infection $(n=5 ; 14 \%)$. Of the 44 patients, $19(43 \%)$ had a Child-Pugh score of 5 and $25(57 \%)$ had a Child-Pugh score of 6. Prior to NFP, 28 (64\%) patients received previous treatment. HCC showed portal vein invasion, with $4(9 \%)$ having main trunk invasion and $40(91 \%)$ having first or second branch invasion, and the mean size was $74.2 \mathrm{~mm}$.

There were no statistically significant differences in the clinical factors between the groups.

Overall response and efficacy. Table II shows the results at the first radiologic assessment according to the RECIST. Of the
20 patients treated with sorafenib, $0(0 \%), 2(10 \%)$, and $8(40 \%)$ patients had $\mathrm{CR}, \mathrm{PR}$, and $\mathrm{SD}$, respectively. The response rate was $10 \%$, and the disease-control rate was $50 \%$.

On the other hand, of the 44 patients treated with NFP, $10(23 \%), 21(48 \%)$, and $8(18 \%)$ patients had CR, PR, and $\mathrm{SD}$, respectively. The response rate was $71 \%$, and the disease-control rate was $89 \%$.

Factors associated with survival outcomes. Cox proportional-hazards regression analysis was performed to identify the independent factors associated with survival (Table III). Univariate analysis of survival identified 4 baseline patient characteristics as prognostic indicators for OS, including Child-Pugh score, grade of portal vein invasion, regimen, and therapeutic effect. Multivariate analysis confirmed that Child-Pugh score [5; $\mathrm{P}=0.022,95 \%$ confidence interval $(C I)=0.191-0.892]$, grade of portal vein invasion (branch; $\mathrm{P}=0.002,95 \% \mathrm{CI}=0.118-0.614)$, and therapeutic effect $(\mathrm{CR} / \mathrm{PR}$; $\mathrm{P}=0.009,95 \% \mathrm{CI}=0.220-0.752$ ) were independent factors for survival.

Cumulative progression-free survival curves of patients treated with either sorafenib therapy or NFP are shown in Fig. 1. The MST was 5.1 months for patients treated with sorafenib therapy and 9.5 months for those treated with NFP $(\mathrm{P}=0.002)$. Cumulative OS curves of patients treated with sorafenib therapy or NFP are shown in Fig. 2. The MST was 13.2 months for patients treated with sorafenib therapy and 30.4 months for those treated with NFP $(\mathrm{P}=0.013)$.

Comparison of patient characteristics based on therapeutic effect. Cox proportional-hazards regression analysis was performed to identify the independent factors associated with therapeutic effect (Table IV). Univariate analysis of the therapeutic effect identified three baseline patient characteristics as prognostic indicators for therapeutic response, including DCP level at baseline, maximum tumor size, and regimen. Multivariate analysis confirmed that maximum tumor size ( $\geq 100 \mathrm{~mm}, \mathrm{P}=0.007,95 \% \mathrm{CI}=1.960-75.10)$ and regimen (NFP, 
$\mathrm{P}<0.001,95 \% \mathrm{CI}=0.006-0.199)$ were independent factors for therapeutic response.

Adverse events. Severe adverse events were observed in 5 patients. In the sorafenib group, 2 patients had hepatic failure, while in the NFP group, 2 patients had hepatic failure and 1 had a pseudo-aneurysm. In the two groups, treatment-related mortality was not observed.

\section{Discussion}

Sorafenib, an oral multi-kinase inhibitor and a new molecular-targeted therapy for advanced HCC has been shown to offer a significant survival benefit with good tolerance in two randomized phase III placebo-controlled trials $(16,17)$. Thus, it has become the standard treatment for advanced HCC. In the SHARP trial, the median overall survival times of all patients and patients with MVI treated with sorafenib were 10.7 and 8.1 months, respectively (16). However, contrary to our expectations, the survival and therapeutic advantages of sorafenib are modest.

PVTT is a common complication in HCC, and it has been reported in $65 \%$ of cases at autopsy (32). PVTT often leads to extensive spreading of the tumor and can increase portal venous blood pressure, resulting in the fatal rupture of esophageal varices (33). PVTT can also decrease portal flow that may lead to ascites, jaundice, hepatic encephalopathy, or liver failure (33). Therefore, the presence of PVTT is one of the most significant prognostic factors of poor outcome $(34,35)$, and it has been reported that these patients survive only $2.7-4$ months if left untreated $(35,36)$. In advanced HCC patients with PVTT, standard treatments have not been established. The prognosis for advanced HCC with PVTT is dismal owing to poor response to current treatment modalities (37). Although the BCLC staging system recommends sorafenib in these patients, its efficacy is limited. In another study, the MST of patients with PVTT was only 5 months (38). Thus, HAIC is considered an alternative treatment modality (38).

The difference between NFP and conventional TACE is the administration of a drug repeatedly from the reservoir system without using embolic material. As embolic material is not used, it becomes possible to enhance the therapeutic effect by repeating the treatment. The difference between NFP and conventional HAI is the use of lipiodol. By using lipiodol, it is possible to temporarily enhance the antitumor effect through the vascular embolic effect.

The response rate and disease-control rate were 10 and $50 \%$ in the sorafenib therapy group, and 71 and $89 \%$ in the NFP group, respectively (Table II). We demonstrated that the therapeutic response rate of NFP was superior to that of sorafenib. The rationale of the cisplatin $+5-\mathrm{FU}$ regimen is that cisplatin and 5-FU have antitumor effects (39), and cisplatin has a synergistic effect as a modulator of 5-FU (40). In the present study, 5-FU was continuously infused for 5 days. 5-FU does not show a dose-dependent effect, but shows a time-dependent antitumor effect (41). Continuous infusion of 5-FU may enhance the antitumor effect in cisplatin-lipiodol plus 5-FU therapy compared with other HAIC regimens. The antitumor effect has been reported to be more potent with anticancer agents in lipiodol suspension than with anticancer agents alone, such as sorafenib (42).

Multivariate analysis identified three baseline patient characteristics as prognostic indicators for overall survival, including the Child-Pugh score, grade of portal vein invasion, and therapeutic effect (Table III). We demonstrated that the therapeutic response was a significant risk factor adversely affecting survival in this study. Consistent with a previous study showing that early radiological progression after treatment predicts poor survival, our patients, who developed early PD, had significantly worse OS (43). Another multivariate analysis identified two baseline patient characteristics as prognostic indicators for therapeutic effect, including maximum tumor size and regimen (Table IV). In our study, patients treated with NFP survived longer than patients treated with sorafenib monotherapy. We demonstrated that the therapeutic response was more effective in patients treated with NFP than in patients treated with sorafenib. HAIC is a reasonable drug delivery system for patients with advanced HCC because advanced HCC receives most of its blood supply from the hepatic artery, and the non-cancerous liver is supplied mainly by the portal vein (44). HAIC appears to deliver high concentrations of chemotherapeutic agents to HCC tissues selectively, with low toxicity for non-cancerous liver tissues and the whole body. Several reports described the effects of HAIC with cisplatin and 5-FU or systemic interferon- $\alpha$ therapy with HAIC using 5-FU for HCC patients with tumor thrombosis in the first branches and the portal vein trunks $(21,45)$. Therefore, we showed that NFP is more effective than sorafenib therapy in patients with advanced HCC and MVI.

The present study has limitations. First, there was no protocol to guide treatment selection. Therefore, the treatments were selected at the discretion of the chief physician and were not randomized. This resulted in a selection bias for patients treated with sorafenib therapy and NFP, although there were no significant differences in the patient characteristics between the two groups. Second, some patients received multiple treatments other than sorafenib therapy or NFP. Third, the modified RECIST criteria should have also been used for the evaluation of tumor response and disease control rate. However, the therapeutic effect was determined according to only the RECIST criteria at the different centers in the sorafenib group. Therefore, we were unable to use the modified RECIST for the evaluation of tumor response and the disease control rate. Lastly, the size of the study cohort was relatively small. To confirm the superiority of NFP over sorafenib in patients with advanced HCC and MVI, prospective randomized studies with a larger number of subjects are required.

In conclusion, our results showed that NFP was a significantly positive prognostic treatment for patients with advanced HCC and MVI. The survival potential was greater in patients treated with NFP than in those treated with sorafenib. Therefore, NFP should be the first choice for patients with advanced HCC and MVI, without EHS and Child-Pugh A disease.

\section{Acknowledgements}

The authors thank the staff of the Kurume Liver Cancer Study Group of Japan for their valuable support. The authors also thank Editage (www.editage.jp) for English language editing. 


\section{References}

1. El-Serag HB and Mason AC: Rising incidence of hepatocellular carcinoma in the United States. N Engl J Med 340: 745-750, 1999.

2. Parkin DM, Bray F, Ferlay J and Pisani P: Global cancer statistics, 2002. CA Cancer J Clin 55: 74-108, 2005.

3. Sherman M: Hepatocellular carcinoma: Epidemiology, risk factors, and screening. Semin Liver Dis 25: 143-154, 2005.

4. Perz JF, Armstrong GL, Farrington LA, Hutin YJ and Bell BP: The contributions of hepatitis $B$ virus and hepatitis $C$ virus infections to cirrhosis and primary liver cancer worldwide. J Hepatol 45: 529-538, 2006

5. Takayama T, Makuuchi M, Hirohashi S, Sakamoto M, Yamamoto J, Shimada K, Kosuge T, Okada S, Takayasu K and Yamasaki S: Early hepatocellular carcinoma as an entity with a high rate of surgical cure. Hepatology 28: 1241-1246, 1998.

6. Nagasue N, Uchida M, Makino Y, Takemoto Y, Yamanoi A, Hayashi T, Chang YC, Kohno H, Nakamura T and Yukaya $\mathrm{H}$ : Incidence and factors associated with intrahepatic recurrence following resection of hepatocellular carcinoma Gastroenterology 105: 488-494, 1993.

7. Liver Cancer Study Group of Japan: Primary liver cancer in Japan. Clinicopathologic features and results of surgical treatment. Ann Surg 211: 277-287, 1990.

8. Jonas S, Bechstein WO, Steinmüller T, Herrmann M, Radke C, Berg T, Settmacher U and Neuhaus P: Vascular invasion and histopathologic grading determine outcome after liver transplantation for hepatocellular carcinoma in cirrhosis. Hepatology 33 : 1080-1086, 2001.

9. Pawarode A, Voravud N, Sriuranpong V, Kullavanijaya P and Patt YZ: Natural history of untreated primary hepatocellular carcinoma: A retrospective study of 157 patients. Am J Clin Oncol 21: 386-391, 1998

10. Llovet JM, Bustamante J, Castells A, Vilana R, Ayuso Mdel C Sala M, Brú C, Rodés J and Bruix J: Natural history of untreated nonsurgical hepatocellular carcinoma: Rationale for the design and evaluation of therapeutic trials. Hepatology 29: 62-67, 1999.

11. Furuse J, Ishii H, Nakachi K, Suzuki E, Shimizu S and Nakajima K: Phase I study of sorafenib in Japanese patients with hepatocellular carcinoma. Cancer Sci 99: 159-165, 2008.

12. Nakano M, Tanaka M, Kuromatsu R, Nagamatsu $H$, Sakata K, Matsugaki S, Kajiwara M, Fukuizumi K, Tajiri N, Matsukuma N, et al: Efficacy, safety, and survival factors for sorafenib treatment in Japanese patients with advanced hepatocellular carcinoma. Oncology 84: 108-114, 2013.

13. Nakano M, Tanaka M, Kuromatsu R, Nagamatsu H, Tajiri N, Satani M, Niizeki T, Aino H, Okamura S, Iwamoto H, et al: Sorafenib for the treatment of advanced hepatocellular carcinoma with extrahepatic metastasis: A prospective multicenter cohort study. Cancer Med 4: 1836-1843, 2015.

14. Wilhelm SM, Adnane L, Newell P, Villanueva A, Llovet JM and Lynch M: Preclinical overview of sorafenib, a multikinase inhibitor that targets both Raf and VEGF and PDGF receptor tyrosine kinase signaling. Mol Cancer Ther 7: 3129-3140, 2008.

15. Wilhelm SM, Carter C, Tang L, Wilkie D, McNabola A, Rong H, Chen C, Zhang X, Vincent P, McHugh M, et al: BAY 43-9006 exhibits broad spectrum oral antitumor activity and targets the RAF/MEK/ERK pathway and receptor tyrosine kinases involved in tumor progression and angiogenesis. Cancer Res 64 7099-7109, 2004.

16. Llovet JM, Ricci S, Mazzaferro V, Hilgard P, Gane E, Blanc JF, de Oliveira AC, Santoro A, Raoul JL, Forner A, et al: Sorafenib in advanced hepatocellular carcinoma. N Engl J Med 359: 378-390, 2008

17. Cheng AL, Kang YK, Chen Z, Tsao CJ, Qin S, Kim JS, Luo R, Feng J, Ye S, Yang TS, et al: Efficacy and safety of sorafenib in patients in the Asia-Pacific region with advanced hepatocellular carcinoma: A phase III randomised, double-blind, placebo-controlled trial. Lancet Oncol 10: 25-34, 2009.

18. Ando E, Yamashita F, Tanaka M and Tanikawa K: A novel chemotherapy for advanced hepatocellular carcinoma with tumor thrombosis of the main trunk of the portal vein. Cancer 79: 1890-1896, 1997.

19. Ando E, Tanaka M, Yamashita F, Kuromatsu R, Yutani S, Fukumori K, Sumie S, Yano Y, Okuda K and Sata M: Hepatic arterial infusion chemotherapy for advanced hepatocellular carcinoma with portal vein tumor thrombosis: Analysis of 48 cases. Cancer 95: 588-595, 2002.
20. Chung YH, Song IH, Song BC, Lee GC, Koh MS, Yoon HK, Lee YS, Sung KB and Suh DJ: Combined therapy consisting of intraarterial cisplatin infusion and systemic interferon-alpha for hepatocellular carcinoma patients with major portal vein thrombosis or distant metastasis. Cancer 88: 1986-1991, 2000.

21. Obi S, Yoshida H, Toune R, Unuma T, Kanda M, Sato S, Tateishi R, Teratani T, Shiina S and Omata M: Combination therapy of intraarterial 5-fluorouracil and systemic interferon-alpha for advanced hepatocellular carcinoma with portal venous invasion. Cancer 106: 1990-1997, 2006.

22. Park JY, Ahn SH, Yoon YJ, Kim JK, Lee HW, Lee DY, Chon CY, Moon YM and Han KH: Repetitive short-course hepatic arterial infusion chemotherapy with high-dose 5-fluorouracil and cisplatin in patients with advanced hepatocellular carcinoma. Cancer 110: 129-137, 2007.

23. Yamasaki T, Kimura T, Kurokawa F, Aoyama K, Ishikawa T, Tajima K, Yokoyama Y, Takami T, Omori K, Kawaguchi K, et al: Prognostic factors in patients with advanced hepatocellular carcinoma receiving hepatic arterial infusion chemotherapy. J Gastroenterol 40: 70-78, 2005.

24. Niizeki T, Sumie S, Torimura T, Kurogi J, Kuromatsu R, Iwamoto H, Aino H, Nakano M, Kawaguchi A, Kakuma T and Sata M: Serum vascular endothelial growth factor as a predictor of response and survival in patients with advanced hepatocellular carcinoma undergoing hepatic arterial infusion chemotherapy. J Gastroenterol 47: 686-695, 2012.

25. Nagamatsu H, Hiraki M, Mizukami N, Yoshida H, Iwamoto H, Sumie S, Torimura T and Sata M: Intra-arterial therapy with cisplatin suspension in lipiodol and 5-fluorouracil for hepatocellular carcinoma with portal vein tumour thrombosis. Aliment Pharmacol Ther 32: 543-550, 2010.

26. Bruix J, Raoul JL, Sherman M, Mazzaferro V, Bolondi L, Craxi A, Galle PR, Santoro A, Beaugrand M, Sangiovanni A, et al: Efficacy and safety of sorafenib in patients with advanced hepatocellular carcinoma: Subanalyses of a phase III trial. J Hepatol 57: 821-829, 2012

27. Eisenhauer EA, Therasse P, Bogaerts J, Schwartz LH, Sargent D, Ford R, Dancey J, Arbuck S, Gwyther S, Mooney M, et al: New response evaluation criteria in solid tumours: Revised RECIST guideline (version 1.1). Eur J Cancer 45: 228-247, 2009.

28. Bruix J, Sherman M, Llovet JM, Beaugrand M, Lencioni R, Burroughs AK, Christensen E, Pagliaro L, Colombo M and Rodés J; EASL Panel of Experts on HCC: Clinical management of hepatocellular carcinoma. Conclusions of the Barcelona-2000 EASL conference. European Association for the Study of the Liver. J Hepatol 35: 421-430, 2001.

29. Forner A, Reig ME, de Lope CR and Bruix J: Current strategy for staging and treatment: The BCLC update and future prospects. Semin Liver Dis 30: 61-74, 2010.

30. Oken MM, Creech RH, Tormey DC, Horton J, Davis TE, McFadden ET and Carbone PP: Toxicity and response criteria of the Eastern Cooperative Oncology Group. Am J Clin Oncol 5: 649-655, 1982.

31. Therasse P, Arbuck SG, Eisenhauer EA, Wanders J, Kaplan RS, Rubinstein L, Verweij J, Van Glabbeke M, van Oosterom AT, Christian MC and Gwyther SG: New guidelines to evaluate the response to treatment in solid tumors. European Organization for Research and Treatment of Cancer, National Cancer Institute of the United States, National Cancer Institute of Canada. J Natl Cancer Inst 92: 205-216, 2000

32. Nakashima T, Okuda K, Kojiro M, Jimi A, Yamaguchi R, Sakamoto K and Ikari T: Pathology of hepatocellular carcinoma in Japan. 232 Consecutive cases autopsied in ten years. Cancer 51: 863-877, 1983

33. Song DS, Bae SH, Song MJ, Lee SW, Kim HY, Lee YJ, Oh JS, Chun HJ, Lee HG, Choi JY and Yoon SK: Hepatic arterial infusion chemotherapy in hepatocellular carcinoma with portal vein tumor thrombosis. World J Gastroenterol 19: 4679-4688, 2013.

34. Park KW, Park JW, Choi JI, Kim TH, Kim SH, Park HS, Lee WJ, Park SJ, Hong EK and Kim CM: Survival analysis of 904 patients with hepatocellular carcinoma in a hepatitis B virus-endemic area. J Gastroenterol Hepatol 23: 467-473, 2008.

35. Okuda K, Ohtsuki T, Obata H, Tomimatsu M, Okazaki N, Hasegawa H, Nakajima Y and Ohnishi K: Natural history of hepatocellular carcinoma and prognosis in relation to treatment. Study of 850 patients. Cancer 56: 918-928, 1985.

36. Villa E, Moles A, Ferretti I, Buttafoco P, Grottola A, Del Buono M, De Santis M and Manenti F: Natural history of inoperable hepatocellular carcinoma: Estrogen receptors' status in the tumor is the strongest prognostic factor for survival. Hepatology 32: 233-238, 2000. 
37. Lin CC, Hung CF, Chen WT and Lin SM: Hepatic arterial infusion chemotherapy for advanced hepatocellular carcinoma with portal vein thrombosis: Impact of early response to 4 weeks of treatment. Liver Cancer 4: 228-240, 2015.

38. Nakano M, Tanaka M, Kuromatsu R, Nagamatsu H, Satani M, Niizeki T, Okamura S, Iwamoto H, Shimose S, Shirono T, et al: Alternative treatments in advanced hepatocellular carcinoma patients with progressive disease after sorafenib treatment: A prospective multicenter cohort study. Oncotarget 7: 64400-64409, 2016.

39. Paquet KJ, Kalk JF, Cuan-Orozco F, Siemens F, Koussouris P and Mercado MA: Hepatic chemoinfusion of 5-FU in metastasis of gastrointestinal cancer and advanced primary hepatocellular carcinoma. Eur J Surg Oncol 18: 156-161, 1992.

40. Hata F, Sasaki K, Hirata K, Yamamitsu S and Shirasaka T: Efficacy of a continuous venous infusion of fluorouracil and daily divided dose cisplatin as adjuvant therapy in resectable colorectal cancer: A prospective randomized trial. Surg Today 38: 623-632, 2008.

41. Okabe H, Toko T, Saito H, Nakano K, Fujioka A, Yuasa C, Takeda $\mathrm{S}$ and Unemi N: Augmentation of the chemotherapeutic effectiveness of UFT, a combination of tegafur [1-(2-tetrahydrofuryl)-5-fluorouracil] with uracil, by oral 1-leucovorin. Anticancer Res 17: 157-164, 1997.
42. Terayama N, Matsui O, Gabata T, Kobayashi S, Sanada J, Ueda K, Kadoya M and Kawamori Y: Accumulation of iodized oil within the nonneoplastic liver adjacent to hepatocellular carcinoma via the drainage routes of the tumor after transcatheter arterial embolization. Cardiovasc Intervent Radiol 24: 383-387, 2001.

43. Iavarone M, Cabibbo G, Piscaglia F, Zavaglia C, Grieco A, Villa E, Cammà C and Colombo M; SOFIA (SOraFenib Italian Assessment) study group: Field-practice study of sorafenib therapy for hepatocellular carcinoma: A prospective multicenter study in Italy. Hepatology 54: 2055-2063, 2011.

44. Breedis C and Young G: The blood supply of neoplasms in the liver. Am J Pathol 30: 969-977, 1954.

45. Itamoto T, Nakahara H, Tashiro H, Haruta N, Asahara T, Naito A and Ito K: Hepatic arterial infusion of 5-fluorouracil and cisplatin for unresectable or recurrent hepatocellular carcinoma with tumor thrombus of the portal vein. J Surg Oncol 80: 143-148, 2002. 